\title{
Helen Salisbury: Small is beautiful
}

\author{
Helen Salisbury GP \\ Oxford
}

This week I learnt that 138 GP surgeries closed their doors for the last time in 2018. ${ }^{1}$ Some of the practices merged, some doctors were employed or became partners elsewhere, and some GPs, wearied and defeated, took early retirement.

Most of the practices affected were small, with lists of fewer than 5000 patients. It's easy to see why smaller practices are vulnerable. A single retirement or episode of ill health can be enough to close a practice if it can't recruit new staff. The ever increasing regulatory burden on primary care is harder to bear if you have only two partners and a part time practice manager. Larger, merged practices may be more resilient in the face of change, and there are some economies of scale, especially in administration. The direction of travel for general practice seems to be towards ever bigger organisations-through networks, super-practices, or corporately owned chains.

When considering the benefits of scale, it's also worth asking what we risk losing. Patients may lose a place that they know and where they are known. Where once they walked to the surgery and greeted the receptionist by name, now they take a bus and see a new face on each visit. They're also less likely to see the same doctor. ${ }^{2}$ This loss of relational continuity isn't just about how patients feel—although familiar places and people probably make it less stressful to seek help and advice. We know that seeing the same doctor at most appointments reduces the likelihood of an avoidable hospital admission, especially among patients who consult frequently. ${ }^{2}$ This makes sense: if I know that my breathless patient also has anxiety but actually his chest is no worse than two weeks ago, I can reassure him confidently.
It's not only patients who risk losing something important in the rush for scale. Many GPs chose their speciality because it offered a chance to treat people, not just diseases, and to come to know their patients over time. A particular satisfaction comes from treating whole families over many years: relationships deepen, trust grows, secret fears are shared, and you go the extra mile willingly for your patients. I admit to being an idealistic, old fashioned GP who wants to know what makes my patient tick, to recognise when something's wrong, and to know what's most likely to help each one. If I worked shifts in the extended hours service I'm confident that I could be a safe and efficient dispenser of medical knowledge, even an empathetic listener, but I'd be doing only half the job I trained for.

If we lose continuity we lose job satisfaction and, with it, our main recruiting tool to general practice. We should be careful.

Competing interests: See www.bmj.com/about-bmj/freelance-contributors. Provenance and peer review: Commissioned; not externally peer reviewed.

Perraudin F. GP surgery closures in UK "hit all-time high" in 2018. Guardian 2019 May 31. https://www.theguardian.com/society/2019/may/31/gp-surgery-closures-in-uk-hit-alltime-high-in-2018.

2 Barker I, Steventon A, Deeny SR. Association between continuity of care in general practice and hospital admissions for ambulatory care sensitive conditions: cross sectional study of routinely collected, person level data. BMJ 2017;356:;84.28148478

Published by the BMJ Publishing Group Limited. For permission to use (where not already granted under a licence) please go to http://group.bmj.com/group/rights-licensing/ permissions 